\title{
Data and phenomena in conceptual modelling
}

\author{
Benedikt Löwe • Thomas Müller
}

Received: 20 May 2009 / Accepted: 3 June 2009 / Published online: 4 July 2009

(C) The Author(s) 2009. This article is published with open access at Springerlink.com

\begin{abstract}
The distinction between data and phenomena introduced by Bogen and Woodward (Philosophical Review 97(3):303-352, 1988) was meant to help accounting for scientific practice, especially in relation with scientific theory testing. Their article and the subsequent discussion is primarily viewed as internal to philosophy of science. We shall argue that the data/phenomena distinction can be used much more broadly in modelling processes in philosophy.
\end{abstract}

Keywords Modelling $\cdot$ Methodology $\cdot$ Metaphilosophy

We would like to dedicate this paper to the memory of our colleague at Bonn, Daniela Bailer-Jones.

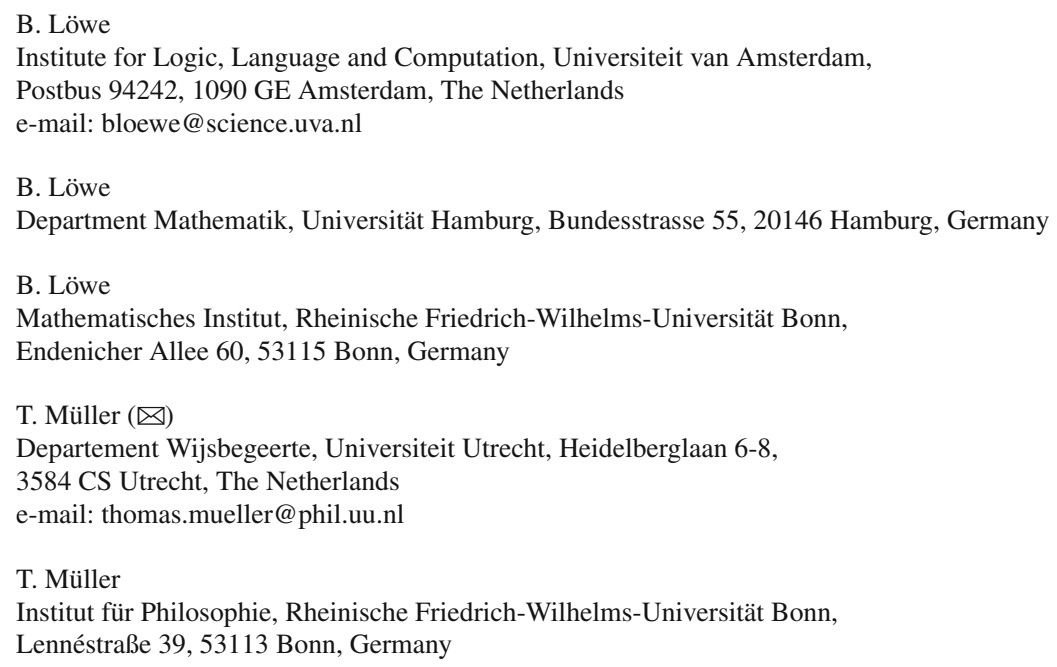




\section{Introduction}

The distinction between data and phenomena introduced by Bogen and Woodward (1988) was meant to help accounting for scientific practice, especially scientific theory testing. Their article and the subsequent discussion is primarily viewed as internal to philosophy of science. In this paper, we apply their distinction to the general technique of conceptual modelling, a widespread methodology that is also employed in philosophy. Distinguishing between data and phenomena will allow us to shed some light on a number of philosophical and metaphilosophical issues: it provides for a stance from which one can assess the status of empirical methods in philosophy, and it helps to distinguish between good and bad uses of the technique of conceptual modelling in specific arguments employed in analytical philosophy.

In Sect. 2, we give a general overview of the technique of conceptual modelling with some examples. In Sect. 3, we introduce our main metaphilosophical issue, viz., the fundamental difficulty that practitioners of philosophy face when doing "philosophy of $X$ ", e.g., philosophy of mathematics, philosophy of language, or the philosophy of time: they have to walk a thin line between two methodological dangers, the Scylla of mere armchair philosophy and the Charybdis of essentially becoming sociologists of $X$. In the context of conceptual modelling, we can give a precise description of these two perils.

After that, in Sect. 4 we provide a recapitulation of the distinction between data and phenomena and show how it captures some fine structure of the method of conceptual modelling. In order to illustrate the general usefulness of making the data/phenomena distinction in philosophy, we give a case study from epistemology and connect to the 1950s discussion about ordinary language philosophy. We then formulate specific lessons for the current debate about the use of experiments and intuitions in philosophy.

Finally, in Sect. 5, we provide our answer to the questions raised in Sect. 3. By using the detailed analysis of potential problems generated by confusing data and phenomena, we propose a means of charting the waters between Scylla and Charybdis, and analyse why the modeller sometimes runs into Scylla and sometimes is swallowed by Charybdis.

\section{Conceptual modelling}

In science and engineering, mathematical modelling has long been seen as one of the most fundamental methodologies and its scope is perceived as growing:

Nowadays, mathematical modelling has a key role also in fields such as the environment and industry, while its potential contribution in many other areas is becoming more and more evident. One of the reasons for this growing success is definitely due to the impetuous progress of scientific computation; this discipline allows the translation of a mathematical model [...] into algorithms that can be treated and solved by ever more powerful computers. (Quarteroni 2009, p. 10)

Mathematical modelling thus presupposes quantitative and computational methods. However, a slight generalization of the same methodology is ubiquitous also in 
non-quantitative research areas. In analogy to mathematical modelling, we call this more general technique conceptual modelling. ${ }^{1}$ Conceptual modelling is an iterative process through which a stable equilibrium is reached between a concept or a collection of concepts as explanandum and a (somewhat) formal representation of it. ${ }^{2}$ Each iteration towards the equilibrium involves three steps:

1. Formal representation. Guided by either some initial understanding of $X$ or the earlier steps in the iteration, one develops a formal representation of the explanandum.

2. Phenomenology. With a view towards step 3, one collects evidence in the range of the explanandum that is ideally able either to corroborate or to question the current formal representation.-We call this step "phenomenology" because it is generally broader than mere data collection; this will become important below, and will be discussed in Sects. 4 and 5 .

3. Assessment. In the light of the results from step 2, one assesses the adequacy of the representation. If this assessment is positive, the modelling cycle is left-no further iteration is necessary since an equilibrium has been reached. Otherwise, the representation has to be changed, and a new iteration is started at step 1 .

This method obviously covers mathematical modelling as employed in the sciences and in engineering, where the formal representation typically comes with a numerical mathematical model that allows for quantitative predictions. In this case, the phenomenology step consists of quantitative experiments and/or observations. Another instance of modelling is given by the iterative schemes of parameter fitting that are often employed in data analysis, where something like the above procedure is implemented in the form of concrete algorithms. In that case, the phenomenology step involves, e.g., the computation of a "goodness of fit" measure (based on the discrepancy between the given data points and the current parameterized model) that is then assessed in order to decide whether convergence has been reached, or whether a new iteration with updated parameters is necessary. It can also be illuminating to describe historical episodes in the sciences in terms of the modelling paradigm, when assessment in the light of new data leads to theory change. As an illustration, one may consider Kepler's two successive theories of planetary orbits, only the second of which (incorporating what is now known as "Kepler's laws") survived assessment in the light of Brahe's astronomical observations (Kuhn 1957). History also provides us with striking examples of the use of conceptual modelling in non-quantitative contexts - consider, e.g., Ventris's deciphering of Linear B starting with the faulty theoretical assumption that

\footnotetext{
1 The use of the word "modelling" calls to mind the debate about theories and models in philosophy of science. This overlap in terminology may be somewhat unfortunate, but first, the entrenchment of the term "mathematical modelling" does not allow another choice of phrase, and secondly, calling the method "modelling" is also adequate from the point of view of that debate, since stressing that one is just after a model does not suggest deep metaphysical involvement. Cf. our remarks about logical analysis (which does suggest such involvement) below, note 3 .

2 When speaking of "formal representation" here, we wish to leave it open whether this representation just employs some predicate-logical symbolization with a view towards regimented natural language, uses a formal language such as the language of modal logic, or specifies a mathematical model of some sort.
} 
the language was not related to Greek (Chadwick 1990). And in philosophy, modelling is a useful generalization of the paradigm of "analysis", as we shall lay out below.

The modelling paradigm is also broad enough to cover two opposite stances with respect to the aim of theory construction: should a theory just account for given observations, or is some deeper insight aimed at? In this debate about "saving the phenomena", one camp joins Osiander's preface to Copernicus's De Revolutionibus in viewing the aim of theory construction to be the establishment of a model that simply reproduces what is observable, thus yielding, in Duhem's words,

[...] a system of mathematical propositions, deduced from a small number of principles, which aim to represent as simply and completely, and exactly as possible, a set of experimental laws. (Duhem 1906, p. 19)

At the other end of the spectrum, one may demand models that are not just empirically, but somehow also structurally appropriate in the sense of capturing the essence of what they are models of. No matter how this demand can be spelled out explicitlywithin our modelling paradigm it clearly refers to a standard of assessment (step 3) that differs from the one in place in the "saving the phenomena" camp.

We already stated that the method of conceptual modelling is not confined to the sciences, nor to quantitative methods. In the case of philosophy one should also note that conceptual modelling is more general and more dynamical than the prominent method of "conceptual analysis". For an overview of this method, we refer the reader to Beaney (2008). ${ }^{3}$ The wider scope of conceptual modelling vis-à-vis conceptual analysis is important, e.g., when it comes to the debate about the use of intuitions in philosophy, which we shall address in Sect.4.3. Thus, in his defense of the use of intuitions in philosophy against some positions of experimental philosophy, Ernest Sosa writes:

It is often claimed that analytic philosophy appeals to armchair intuitions in the service of "conceptual analysis". But this is deplorably misleading. The use of intuitions in philosophy should not be tied exclusively to conceptual analysis. Consider some main subjects of prominent debate: utilitarian versus deontological theories in ethics, for example, or Rawls's theory of justice in social and political philosophy [...]. These are not controversies about the conceptual analysis of some concept. [...] Yet they have been properly conducted in terms of hypothetical examples, and intuitions about these examples. (Sosa 2007, p. 100)

All the philosophical debates that Sosa mentions as falling outside the scope of conceptual analysis do fall under the scope of the more general technique of conceptual

\footnotetext{
3 The well-known distinction between "theory" and "model" in philosophy of science (cf. note 1) is approximately reflected in the distinction between "conceptual analysis" and "conceptual modelling". At least on a certain reading, analysis is meant to render an initially imprecise and vague problem in its 'true' logical form via the reduction of natural language to formal logic. On the other hand, the technique of conceptual modelling makes no claims about the relationship between the model and the described concept other than adequacy in the context at hand, thus staying closer to the rôle of models in science.
} 
modelling. The use of intuition can therefore be addressed more adequately within that framework. ${ }^{4}$

Let us add a disclaimer at this point: Even though conceptual modelling is broader than conceptual analysis, we do of course realize that conceptual modelling is not the only method of philosophy. There are philosophical argumentation techniques that will not fit into our general scheme. Our claim is just that conceptual modelling is widespread enough to guarantee that understanding the metaphilosophical implications and details of this particular philosophical technique will greatly advance our understanding of philosophical practice in general-even if some aspects of philosophical methodology are not covered.

\section{3 "What is a philosophy of $X$ ?"}

One of the hardest methodological challenges in philosophy is to give an account of what one is doing in establishing a "philosophy of" something that is already there. 5 Philosophical theory building often starts out with a normative agenda, which threatens to lose touch with what the theory is to be about. On the other hand, a purely descriptive approach can be criticised for failing to be distinctively philosophical. Is there a safe passage for "philosophy of $X$ ", generally, between the Scylla of normative subject-blindness and the Charybdis of merely descriptive non-philosophy?

One can fruitfully read the historical development of philosophy of science in the twentieth century as a searching party in these difficult waters. Broadly speaking, philosophy of science as a separate subfield of philosophy started out from the movement of logical empiricism in the 1920s. In their denial of metaphysics, these philosophers only acknowledged a formal reconstruction task for philosophy, as stated forcefully by Carnap:

Philosophie betreiben bedeutet nichts Anderes als: die Begriffe und Sätze der

Wissenschaft durch logische Analyse klären. (Carnap 1930, p. 26) ${ }^{6}$

Carnap would certainly reject as metaphysical the suggestion that the aim of logical analysis - and thus, on his view, of philosophy — should be to capture the essence of science. But logical analysis demands more than "saving the phenomena" in terms of a description of actual scientific practice: it is meant to give a rational reconstruction, not just a description, of such practice. ${ }^{7}$ Thus, philosophy of science started out dangerously close to Scylla, as a purely normative enterprise in which logical methods were employed to build up a reconstructed version of science without any direct

\footnotetext{
4 Kuipers (2007) also stresses the fact that in analytical philosophy and especially in philosophy of science, a method broader than (static) conceptual analysis is often employed. He discusses this fact in the context of a broadening of the understanding of the method of explication originally proposed by the logical empiricists. Our framework of conceptual modelling is broader than the notion of explication, but shares its dynamical nature.

5 A subcase of this challenge is the so-called "paradox of analysis"; cf. again Beaney (2008).

6 "To pursue philosophy means nothing but: clarifying the concepts and sentences of science by logical analysis."

7 Cf. our remarks in notes 1 and 3 above.
} 
link to science as actually practiced. ${ }^{8}$ The historical turn that philosophy of science took in the 1960s pushed the field towards the other extreme. While close attention to actual scientific practice was certainly a necessary corrective moment, critics saw philosophy of science dissolve into history or sociology. In the meantime, however, philosophy of science seems to have settled for a healthy compromise between the two extremes: historical case studies and sociological findings are generally taken seriously, but philosophy of science has not collapsed into history or sociology. These disciplines are rather seen as informing the field by providing material for philosophical reflection. While it would be an overstatement to claim that there was a universally accepted methodological agreement as to the importance of such empirical input, there is clearly a consensus among philosophers of science that good philosophical work needs to steer a course between a merely normative and a merely empirical approach. Overall it seems that we have here a success story of establishing a "philosophy of $X$ " in one specific case. Can this be generalized?

In the case of a philosophical approach using the method of conceptual modelling, one can already identify Scylla and Charybdis in the three step process described above: by the way in which the phenomenological step (step2) is performed, a philosopher decides how close he or she wants to maneuver towards either of the dangers.

An extreme case of armchair philosophy would base the phenomenology solely on introspective truth, using just the philosopher's own intuition as basis for the following assessment step-if such a step is performed at all. Especially if the philosopher is not an expert of $X$, this is steering dangerously close to Scylla, as one may be losing touch with the subject of investigation at issue. On the other hand, an empirically based approach will involve a data collection step that will provide a description of human behaviour with respect to $X$. However, how do we guarantee that this gives us more than just a description of human behaviour? How do we salvage the philosophical content of our theory?

The current debate about the use of empirical methods in philosophy, under the heading of experimental philosophy, can usefully be described in our framework: it shows a normative ("armchair") and a descriptive ("experimental") camp pulling in different directions, corresponding to different ideas as to what a sound phenomenology step in conceptual modelling should look like. We shall address this debate in more detail in Sect. 4.3 below, making use of the data/phenomena distinction.

\section{Data vs. phenomena in science-and in philosophy}

Bogen and Woodward (1988) famously distinguish data—local, situated facts—-from phenomena - the empirical material against which theories are tested:

\footnotetext{
${ }^{8}$ The matter is of course more diverse than this brief sketch suggests. For one thing, there were other historical developments that added to what became philosophy of science as we know it—one only has to think of the French school initiated by Poincaré. And on the other hand, as Uebel (2001) and Nemeth (2007) point out, the "left wing" of the Vienna circle itself, one of the birthplaces of logical empiricism, didn't just incorporate Carnap's movement of logical reconstruction, but also Neurath, who was much more open to sociological investigations - closer to the "saving the phenomena" attitude indeed; but then, closer to Charybdis, too.
} 
Data, which play the role of evidence for the existence of phenomena, for the most part can be straightforwardly observed. However, data typically cannot be predicted or systematically explained by theory. By contrast, well-developed scientific theories do predict and explain facts about phenomena. Phenomena are detected through the use of data, but in most cases are not observable in any interesting sense of that term. (Bogen and Woodward 1988, p. 305f.)

Bogen and Woodward show through a number of case studies that the step from data to phenomena is indeed crucial for scientific practice, and that specific local skillsknowledge of possible confounding factors or about the quirks of individual scientific instruments - are needed to make that step. In their simplest case study, they take up an example that Ernest Nagel, a defender of the normative approach to philosophy of science of the 1950s, discusses in his influential book The Structure of Science (Nagel 1961, p. 79): measuring the melting point of lead. Nagel suggests that the sentence "lead melts at $327^{\circ} \mathrm{C}$ " is a statement about an observation. Bogen and Woodward show, however, that an individual observation of a sample of lead's melting first needs to be put into its local context, a requirement reminiscent of the traditional hermeneutical rule of "sensus totius orationis" or "semantic holism". " Without going into the details, making one such observation in a laboratory involves a number of technical and subjective factors that are crucial for the interpretation of the resulting single data point. Many such observations pooled together may allow one to infer to the existence of a stable phenomenon, which would then be expressed by the given sentence, "lead melts at $327^{\circ} \mathrm{C}$ ". It is this phenomenon that, e.g., a quantum-mechanical model of the crystal structure of lead would have to explain - and not a single thermometer reading, which may be influenced by, e.g., draught in the laboratory because of someone's entering and opening the door. A skilled experimenter knows about such and other confounding factors (in one case Bogen and Woodward cite, involving the experimenter's boss's heavy steps on the stairwell), and takes them into account prudently when inferring to the existence of phenomena. Ex post it may well be possible to capture such effects systematically via appropriate mini-theories describing a certain class of observational effects, and anticipating them appropriately is a prerequisite of good experimental design. The structure of the actual lab work however always remains open for all kinds of unforseen interventions, and accordingly, there is no formal recipe for the step from data to phenomena.

We claim that the data/phenomena distinction makes sense not just within philosophy of science, but in all cases in which the technique of conceptual modelling is employed. The distinction allows one to discern some fine structure within the phenomenology step, which is not just a step of data collection. The actual work (the empirical work in the lab, the historical work in the archive, the sociological work with questionnaires or interviews - but also armchair introspection) indeed just leads to data: idiosyncratic local facts. However, from these, stable and reproducible phenomena have to be distilled in order to be put up against the theory at issue in the

\footnotetext{
9 Cf. (Scholz 2001, p. 71) or (Bühler and Cataldi Madonna 1996); e.g., "ein Wort hat nur eine Bedeutung keinen Sinn, ein Saz (sic) an und für sich hat einen Sinn aber noch keinen Verstand, sondern den hat nur eine völlig geschlossene Rede" (Schleiermacher 1838, p.41).
} 
modelling cycle. ${ }^{10}$ A phenomenology step that leaves out this move amounts to mere data collection - it is incomplete and can lead to a wrong assessment.

Before we move on to employ the data/phenomena distinction in addressing the general question about "philosophy of $X$ " discussed in the previous section, we shall now illustrate its usefulness via two short case studies. We shall first show how the distinction can be used in epistemology by addressing the question of the factivity of knowledge (Sect.4.1). Secondly, we shall comment on a specific discussion about ordinary language philosophy in the late 1950s (Sect. 4.2). More generally, we will then point to some lessons for the proper place of intuition and experiment in conceptual modelling (Sect. 4.3).

\subsection{Empirical questions in epistemology}

Many central questions of epistemology center around the concept of knowledge: what knowledge is, which knowledge we have or can acquire in which circumstances, and how knowledge relates to truth, belief, and justification. It seems obvious that there is a link between these questions and empirical facts about knowledge attributions, which may be specific utterances of " $X$ knows that $p$ ". After all, philosophers are interested in the concept of knowledge because people think and talk about knowledge-if we had no use for knowledge attributions, the field of epistemology probably wouldn't be there. Also quite plausibly, the socially acknowledged attribution of knowledge of $p$ to $X$ would appear to be a good guide as to whether some person $X$ actually knows some $p$. Surely the link will not be strict-people make mistakes, and there can be pragmatic factors bringing about non-literal uses of such attributions (after all we know that "Can you pass the salt?" isn't a question about physical ability either). But if socially acknowledged attribution of knowledge was systematically talking about a phenomenon (sic!) different from knowledge, why wouldn't philosophers investigate that concept instead? Shouldn't there at least be some link between the utterances and the philosophical theory?

The debate about such a link is rather fierce. Some epistemologists favour a completely normative and a priori approach to knowledge that would not acknowledge the relevance of actual usage_cf., e.g., Hazlett (2009) for an overview. In this camp, the nature of knowledge is held to be fixed by philosophical theory derived via an armchair method based on singular intuitions and introspection. Actual knowledge attributions are then assessed pragmatically, i.e., for cases in which philosophical epistemology and actual use differ, a pragmatic rule is invoked to explain the discrepancy. Such a philosophical analysis is in danger of becoming revisionist philosophy of knowledge by claiming that knowledge assertions in natural language are not about the concept called "knowledge" in philosophy, but about some other concept that happens to be called the same in natural language. According to this extreme view, native speakers using the verb "to know" are referring to this other concept, and their usage has no bearing whatsoever on epistemology. At the other extreme, a purely empirical analysis

\footnotetext{
10 In fact, phenomena usually play a double rôle in modelling: from the theory, one derives predicted phenomena which can then be compared with the phenomena derived from the data, and any discrepancy here will be important for the third modelling step of assessment.
} 
of the natural language usage of "to know" clearly loses its philosophical component and becomes a mere description of speaker behaviour.

Let us illustrate this opposition by the question of the factivity of knowledge, i.e., the question of whether one can know only that which is true. Most a priori philosophical theories of knowledge hold on to this principle, while some contextualist theories deny it. It is a plain empirical fact that people sometimes use knowledge attributions, and apparently felicitously, in a way that denies the factivity of knowledge. ${ }^{11}$ What are we to make of this?

From the point of view of conceptual modelling, it becomes clear that we are here confronted with a debate about the phenomenology step of modelling and about its assessment. Proponents of an a priori theory of factive knowledge may downplay the importance of the empirical material by pointing out that people are sometimes confused about the concepts they employ (which is certainly true), by giving an alternative, pragmatic reading of the knowledge attributions under consideration, or by simply insisting that such examples are philosophically irrelevant. Proponents of a more descriptive approach, on the other hand, may remain unimpressed and point to the undeniable empirical data, accusing the apriorist of an isolating strategy and of reliance on a single data point gathered via introspection.

In this debate, the data/phenomena distinction can be employed to do more justice to both sides, and perhaps to advance the state of the discussion. (We refrain from taking sides here.) The facts that the descriptivists point to are first and foremost data-observable, but local and idiosyncratic facts that do not have the status of theoretically relevant phenomena yet. A further step is necessary here-and even internal consistency of the data after averaging out random errors isn't enough: there can be systematic, not just random errors in data collection. ${ }^{12}$ Let us thus assume that knowledge of $p$ was attributed to $X$ in a certain situation (this already demands a certain interpretation of the words uttered, since irony, play-acting etc. have to be excluded), and that nobody complained even though $p$ was false. Let us assume that a number of such data have been accumulated. When can we infer from there to an epistemologically relevant phenomenon of non-factivity of knowledge?

We pointed out above that the move from data to phenomena is one that requires skill and acquaintance with the local idiosyncrasies of the data. For the case at hand this means that one will have to pay close attention to the local circumstances in which the data (the knowledge attributions) were recorded. The main confounding factor is the possibility of a pragmatic reading of the knowledge attribution. If in a given case a recorded knowledge attribution has a pragmatic explanation-and there are such cases-, then it will not corroborate the phenomenon of non-factive knowledge. One should however observe that the onus of proof in such cases is on the normative

\footnotetext{
11 Hazlett (2009) gives the example "Everyone knew that stress caused ulcers, before two Australian doctors in the early 80 s proved that ulcers are actually caused by bacterial infection", saying that this sentence "does not strike ordinary people as deviant, improper, unacceptable, necessarily false, etc.". Further examples along these lines are easy to find. For some empirical evidence for the non-factive use of "to know" in mathematical practice cf. Müller-Hill (2009) and Löwe et al. (2009).

12 E.g., in measuring the melting point of lead, one might be using a wrongly calibrated thermometer, or consistently misjudge the visual signs of melting. To repeat, the step from data to phenomena isn't automatic.
} 
theoretician. As Austin (1956) knew, ordinary use may not have the last word, but it does have the first.

Generalizing from the specific example, we see that an a priori approach can be correct in criticizing purported empirical refutations of a philosophical theory by single cases and in dismissing them as reports of idiosyncratic usage. This holds good as long as the empiricists have not identified phenomena but are merely relying on data. As soon as a stable and philosophically relevant phenomenon is identified that challenges the a priori theory, however, the empiricist has a valid point against the theory.

\subsection{On the phenomenological basis of ordinary language philosophy: Mates vs. Cavell in 1958}

In this subsection, our topic is the question of the nature of the factual foundation of the ordinary language philosophy of the 1950s. We shall discuss the debate between Mates (1958) and Cavell (1958). ${ }^{13}$ In the 1950s, much of analytic philosophy had taken a linguistic turn towards ordinary language, apparently following Wittgenstein's maxim, "Denk nicht, sondern schau!". The idea was that many philosophical problems should be resolvable through analysis of language as ordinarily practiced-after all, Wittgenstein had also taught that philosophy was language's going on holiday. ${ }^{14}$ Reverting to ordinary use should thus expose many philosophical problems as spurious.

If this is to be the method of philosophy, one obvious question is where the facts about ordinary use come from. Benson Mates (1958) asks this question and argues that an empirical approach is necessary: statements about ordinary use are empirical statements and as such should be addressed, e.g., by the methods of empirical linguistics. ${ }^{15}$ Stanley Cavell (1958), Mates's co-symposionist at the 1957 APA Pacific meeting from which both papers ensued, however claims that it is a mistake to view such statements as straightforwardly empirical. According to him, a native speaker has a form of access to facts about ordinary use that is different from and philosophically much more pertinent than nose-counting.

One of Mates's main points- to which, as far as we can see, Cavell has no direct response-is that the philosophical access to the pertinent facts seems to lead to incompatible results. It may be worth quoting at length; the context of the discussion is an assessment of Ryle's claim that (most of) the problem of free will comes from disregarding the ordinary use of the term "voluntary", which according to him only really applies to "actions which ought not to be done" (Ryle 1949, p. 69). Mates comments:

[T] he intuitive findings of different people, even of different experts, are often inconsistent. Thus, for example, while Prof. Ryle tells us that "voluntary" and "involuntary" in their ordinary use are applied only to actions which ought not

\footnotetext{
13 We should like to thank Jim Bogen for drawing our attention to this material.

14 "Philosophische Probleme entstehen, wenn die Sprache feiert" (Wittgenstein 1953, para. 38).-The "don't think, but look" maxim is from para. 66.

15 Mates in fact envisages at least two methodological ways of accessing such facts, cf. (Mates 1958, p. 165). We shall not go into any detail here.
} 
to be done, his colleague Prof. Austin states in another connection: “... for example, take 'voluntary' and 'involuntary': we may join the army or make a gift voluntarily, we may hiccough or make a small gesture involuntarily ..." If agreement about usage cannot be reached within so restricted a sample as the class of Oxford Professors of Philosophy, what are the prospects when the sample is enlarged? (Mates 1958, p. 165)

Well, how should this question about ordinary use be resolved - and what is the proper methodological place of statements about ordinary use in philosophical arguments anyhow?

Again, our main point here is not to try and resolve these questions, but to point to the usefulness of the data/phenomena distinction in modelling. Statements about ordinary use are first and foremost data. This holds no matter whether such statements are established by empirical investigation (be it nose-counting or interactive interviews) or by armchair introspection exposing intuitions. What is needed in the iterative scheme of conceptual modelling, on the other hand, is stable phenomena. The question of how and when given data may be used to infer to the existence of phenomena is, as always, a delicate one. As in the epistemology case from Sect. 4.1, empirical data about usage may be open to pragmatic maneuvers that explain away observed linguistic behaviour as not pertinent to a given philosophical question. And it is true that a competent speaker of a language, as a member of the community whose practice it is to speak that language, has a special access to that practice that allows him or her to say "we do it like this" that may not need empirical support-Cavell (1958) gives a detailed exposition of this view. One should however acknowledge the methodological pluralism that is now standard in linguistics: according to Karlsson's (2008), "grammatical intuition [...] is accessible by introspection, elicitation, experimental testing, and indirectly by observation of language data". In this way, conflicting native speakers' intuitions can be resolved by collecting more data from various sources-a standard move in inference to the existence of phenomena in the sciences (Bogen and Woodward 1988). As in the lab, so in philosophy, data only make sense if their local context is properly taken into account, and the touchstone for theories consists of phenomena, not of data.

\subsection{On the proper place of experiment and intuition in conceptual modelling}

The discussion between Mates and Cavell outlined in Sect.4.2 is a precursor of a current and very intense metaphilosophical debate about the rôle of intuition and experiment in philosophy. In the last section, we linked the discussion from the 1950s to the data/phenomena distinction, and similarly, we can also locate it as a crucial but neglected factor in the current debate, at least for philosophical approaches in the paradigm of conceptual modelling-which covers a great part of the locus of the current metaphilosophical debate; viz., analytical philosophy.

In the mentioned debate, we find two opposed camps whose extremes correspond roughly to Scylla and Charybdis from Sect. 3. Situating the discussion explicitly within the conceptual modelling framework and insisting on the data/phenomena distinction 
will help us to identify what is going on in this debate and to develop criteria for assessing whether a use of intuition or experiment is problematic or not.

Experimental philosophers have attacked the use of intuition and introspection, claiming that these are too much dependent on external factors to be philosophically relevant. To take just one example, Weinberg et al. (2001) describe a cluster of empirical hypotheses about epistemic intuitions (e.g., "Epistemic intuitions vary from culture to culture") and then argue that "a sizeable group of epistemological projects [...] would be seriously undermined if one or more [...] of [these] hypotheses about epistemic intuitions turns out to be true" (Weinberg et al. 2001, p. 429). They then provide empirical data that suggests that these hypotheses are in fact true. ${ }^{16}$ In general, some experimental philosophers believe that intuitions are only "suited to the task of providing an account of the considered epistemic judgements of (mostly) well-off Westerners with Ph.D.'s in Philosophy" (Bishop and Trout 2005, p. 107).

Critics of experimental philosophy read this as a complete denial of the philosophical relevance of intuition. Against this they stress the fact that sometimes the experimentally observed disagreement is merely verbal and not substantive (Sosa 2007, p. 102), that "dialogue and reflection" rather than singular and possibly idiosyncratic introspection have "epistemological authority" (Kauppinen 2007, p. 113) ${ }^{17}$ and that "intuitions involve the very same cognitive capabilities that we use elsewhere" (Williamson 2004, p. 152).

In slightly differing ways, both Sosa and Williamson stress the analogy between the philosophical use of intuitions and other methods of scientific endeavour:

[I]ntuition is supposed to function [ ...] in philosophy [...] by analogy with the way observation is supposed to function in empirical science. (Sosa 2007, p. 106)

Metaphilosophical talk about intuitions [...] conceals the continuity between philosophical thinking and the rest of our thinking. (Williamson 2004, p. 152)

We believe that the discussion about the rôle of intuition and experiment in philosophy can benefit from the two methodological points that we have argued for in this paper. First, viewing philosophical arguments as cases of conceptual modelling helps to understand the rôle that intuition or experiment are supposed to play: they constitute part of the phenomenology step. Sosa and Williamson in their respective ways are right in stressing the analogy with the sciences here. Second, making the data/phenomena distinction helps to see that there is nothing wrong with intuition, nor with experiments,

\footnotetext{
16 As just one example, they tested a Gettier-style story (similar to the ones discussed in Sect. 5.1 below) about Jill driving an American car on Western and East Asian test subjects. While the Western subjects agreed with the mainstream philosophical opinion that no true knowledge exists in a Gettier-style situation, the majority of East Asian subjects disagreed (Weinberg et al. 2001, Sect. 3.3.2). For further results concerning dependence of intuitions on the order of presentation of stories, cf. also Swain et al. (2008).

17 Kauppinen (2007) also criticizes the experimentalists for using non-participatory questionnaire methods. Note that there are other, qualitative and participatory methods of the social sciences that may be better and more reliable ways of inferring philosophically relevant phenomena. Of course, experimental philosophers are to blame if they do not employ the full richness of methods available in the empirical social sciences.
} 
as such. ${ }^{18}$ Both are methods for arriving at data: local, idiosyncratic facts. Introspection at first tells us only something about the intuitions of one particular human being, the philosopher; similarly, experiments give us data about particular individual human beings. It is the move to stable phenomena that makes all the difference. Both intuition and experiment are problematic if the assessment step of modelling uses just data and not stable phenomena, or if the distinction is not made at all. ${ }^{19}$

It is interesting to note that the discussion about intuition in philosophy has its direct cognate in the meta-discussion in linguistics where the rôle of native speaker intuitions about grammaticality has been questioned. ${ }^{20}$ While looking at this analogy, it should strike the philosopher as interesting that native-speaker intuition in linguistics is a different concept from the philosopher's intuition in many examples of analytic philosophy: we already quoted Karlsson's (2008) point about the multiple accessibility of grammatical intuition. Using native-speaker intuitions in linguistics is methodologically sound because they can be corroborated as phenomena rather than data by elicitation and testing. The problem with philosophical intuition is that very often this seems to be not the case-and papers such as Weinberg et al. (2001) (even if one may be sceptical about their methodology) show that there is a problem. If one is not able to identify a phenomenon behind the intuitions one refers to-and such a phenomenon has to be stable across cultural differences to be philosophically relevant-, then something is amiss.

\section{Assessing instances of conceptual modelling}

In Sect. 3, we discussed the Scylla of divorcing philosophy of $X$ from $X$ and the Charybdis of transforming philosophy of $X$ into an empirical analysis of human dealings with $X$. From our discussion, it is clear that philosophy of $X$, when conducted in the style of conceptual modelling, will have to maneuver between these two perils in all three modelling steps. This provides us with a kind of checklist for assessing instances of conceptual modelling in philosophy.

1. Formal representation. In this step one has to strive for a representation that is properly philosophical—not just any representation of aspects of $X$ will do. What counts as properly philosophical, or as philosophically interesting, also has to do with the historical development of the subject of philosophy. As is well known, what now is physics used to be philosophy a few hundred years ago. Nowadays, when one envisages, e.g., a philosophy of matter, many questions will just be outside of the scope of a philosophical representation and threaten to move one into the whirlpools of Charybdis.

\footnotetext{
18 In this assessment we thus join the balanced view of Symons (2008).

${ }^{19}$ For a clear example of running the two together, cf. Kauppinen (2007). Grundmann (2003) asks for broadening the range of data to be used in philosophy ("die Datenbasis [ ...] erweitern", p. 50). Our point is that it isn't the amount of data but data that allow for the isolation of stable phenomena, which makes the crucial difference.

${ }^{20}$ Cf. Schütze (1996), Sect. 2.4, entitled "Introspection, Intuition and Judgment", which starts with a quotation by Raven McDavid: "Being a native speaker doesn't confer papal infallibility on one's intuitive judgements".
} 
2. Phenomenology. Especially in this step, the two mentioned dangers both pose a genuine threat. Collecting phenomena without philosophical relevance will push the modeller away from the field of philosophy, while failing to collect phenomena in the field of $X$ will cause the modeller to falter at the rock of Scylla. The latter can happen in two different ways: either by collecting phenomena that fall outside of the scope of $X$, of, even worse, by failing to infer stable phenomena from the data about $X$ that one has collected.

3. Assessment. The dangers in this step are related to those of the previous step. Mistaking data for phenomena, or failing to make the distinction, is widespread in philosophy, leading to a premature end of the modelling cycle. In many instances, the assessment step is even lacking altogether, which means that the cyclical nature of modelling is not taken seriously.

As an application of our methodological results, we shall now look at cases of good and bad conceptual modelling by discussing the phenomenology step of three wellknown philosophical arguments. This will allow us, finally, to comment on a certain feeling of dissatisfaction with current analytic philosophy.

\subsection{Stopped clocks and bogus barns}

The question of whether knowledge is (nothing but) justified true belief, has been addressed by a number of philosophers. One purported example of justified true belief that is not knowledge, dating from before the famous paper of Gettier (1963), is by Russell:

There is a man who looks at a clock which is not going, though he thinks it is, and who happens to look at it at the moment when it is right; this man acquires a true belief as to the time of day, but cannot be said to have knowledge. (Russell 1948, p. 170f.)

This example plays its rôle in the phenomenology step of modelling the concept of knowledge. If it points to a true phenomenon of justified true belief without knowledge, then knowledge cannot be (nothing but) justified true belief. How are we to assess this case?

In the case of a stopped clock, we have stable natural language intuitions. Clocks stop all the time, and we deal with such situations in everyday life. Telephone calls and e-mail discussions across several time zones give us experience in handling temporal shift and subtle linguistic means of dealing with the fact that the subjective time for different speakers may be different. This experience in turn allows us to confidently claim intuitions in the case of a stopped clock. In this case, thus, an appeal to natural language intuition ("cannot be said to have knowledge") is enough to infer to the existence of the relevant phenomenon. In the larger context of modelling knowledge, this means that the theory at issue is refuted and that a new modelling cycle has to begin.

In epistemology, many other examples of justified true belief without knowledge have been discussed, but not all of them are equally well supported. Consider Goldman's (or Ginet's) bogus barn example: 
Henry is driving in the countryside with his son. [...] Suppose we are told that, unknown to Henry, the district he has just entered is full of papier-mâché facsimiles of barns. These facsimiles look from the road exactly like barns, but are really just facades, without back walls or interiors [...] Henry has not encountered any facsimiles; the object he sees is a genuine barn. But if the object on that site were a facsimile, Henry would mistake it for a barn. Given this new information, we would be strongly inclined to withdraw the claim that Henry knows the object is a barn. (Goldman 1976, p. 772f.)

Again, our natural language intuitions ("we would be strongly inclined ...") are invoked before he background of a hypothetical situation. Goldman's data point stands: he would not say that Henry has knowledge in that case. Are we allowed to make the step to the existence of the relevant phenomenon here, too?

This case seems to be more doubtful-too much depends on fine details of the story. In the given story, Henry has just entered fake barn country, he sees a real barn; why shouldn't he know it is one? Contrast this with a case in which he has already been misled (unknowingly); our intuitions may shift. In a well-conducted instance of conceptual modelling, this situation should prompt us to look for more data to corroborate the phenomenon in question. Typically, an experiment might be called for at this stage — or the switch to a different example, like Russell's, which leads one to a relevant phenomenon more directly. ${ }^{21}$

\subsection{Mad pain and Martian pain}

On the way to making a point about the mind-body problem, David Lewis opens his paper on "Mad pain and Martian pain" as follows:

There might be a strange man who sometimes feels pain, just as we do, but whose pain differs greatly from ours in its causes and effects. Our pain is typically caused by cuts, burns, pressure, and the like; his is caused by moderate exercise on an empty stomach. Our pain is generally distracting; his turns his mind to mathematics, facilitating concentration on that but distracting him from anything else. $[\ldots][\mathrm{H}]$ e feels pain but his pain does not at all occupy the typical causal role of pain. He would doubtless seem to us to be some sort of madman [...]

I said there might be such a man. I don't know how to prove that something is possible, but my opinion that this is a possible case seems pretty firm. If I want a credible theory of mind, I need a theory that does not deny the possibility of mad pain. (Lewis 1983, p. 122)

Lewis thus introduces the possibility of mad pain and goes on to use it as a touchstone for a theory of mind, he speaks of "the lesson of mad pain" being an argument against

\footnotetext{
21 For Goldman, the Gettier nature of the case is only one of the relevant aspects, which is why Russell's example wouldn't be enough for the purpose of his paper.
} 
functionalism (p. 123). In so doing he treats that possibility as a phenomenon. We may grant that already the possibility, not just the actual existence, of a case of mad pain has intriguing consequences for the philosophy of mind, as Lewis claims. Within our modelling framework, we can however also assess how successful Lewis has been in establishing the existence of the phenomenon in question. He states that he doesn't know "how to prove that something is possible"-read: how to establish the possibility of something as a phenomenon. Now clearly there are established methods for this task; medieval philosophers already knew that ab esse ad posse valet consequentia. Lewis however does not point to an actual case, or even just to a case that is relevantly similar. Instead he argues in favour of his supposition from the fact of his "pretty firm" conviction of the possibility in question; he later repeats that he is concerned here with his "naive opinions about this case" (p. 129). Lewis thus brings forward a piece of data - and a relevant one too. However, by this he has not succeeded in establishing the phenomenon that he needs for his argument against functionalism. Since Lewis in the mentioned article gives no further support for the possibility that he presupposes, his argument should be rejected as methodologically unsound-which, of course, is not the same as rejecting its conclusion.

\subsection{Dissatisfaction with current analytic philosophy}

Having assessed a few 'first-level' philosophical arguments from the methodological perspective provided in this paper, we also mean to provide a (partial) explanation of why some philosophers may think that current analytic philosophy is taking a wrong turn. We can discern and explain two reasons. First, a substantial amount of research results is negative, consisting in the refutation of theories of other people. This is to some extent built into the method of conceptual modelling, which is falsificationprone: any model can be challenged by more data, and challenging the model of a different researcher is easier than coming up with your own model. Secondly, however, the negative image of such research has another, more problematic source: the refutations of theories of other philosophers often involve counterexamples piled on top of each other in thought-experiments dealing with fictitious universes populated with bizarre creatures and objects, such as Martians deploying M-rays (Mele 2003, Chap. 2), zombies (Chalmers 1996), twin earthlings (Putnam 1975), or watchful angels with a dislike for particular glassware (Johnston 1992). Many people feel that they are losing their grip on what such examples can prove, and would generally question the merit of science fiction in philosophy. ${ }^{22}$ Our analysis allows us to go beyond this vague feeling of dissatisfaction with such thought-experiments, and explain why certain cases are unproblematic and others correspond to a faulty phenomenology step. The data-i.e., that some philosopher is convinced by a certain story and another isn't—can be acknowledged, no war about personal intuitions need be fought. The important question is, rather, whether from such stories we may infer not just to data, but to phenomena.

\footnotetext{
22 Remember that Wittgenstein went for Westerns.
} 
Acknowledgements The authors acknowledge the support of the Deutsche Forschungsgemeinschaft for the Wissenschaftliches Netzwerk PhiMSAMP (MU1816/5-1).

Open Access This article is distributed under the terms of the Creative Commons Attribution Noncommercial License which permits any noncommercial use, distribution, and reproduction in any medium, provided the original author(s) and source are credited.

\section{References}

Austin, J. L. (1956). A plea for excuses. In Proceedings of the Aristotelean Society, 57, 175-204.

Beaney, M. (2008). Analysis. In: E. N. Zalta (Ed.), The Stanford Encyclopedia of philosophy. Winter 2008 Edition. stanford, CA: CSLI. http://plato.stanford.edu/archives/win2008/entries/analysis/

Bishop, M. \& Trout, J. (2005). Epistemology and the psychology of human judgment. Oxford: Oxford University Press.

Bogen, J. \& Woodward, J. (1988). Saving the phenomena. Philosophical Review 97(3), 303-352.

Bühler, A. \& Cataldi Madonna, L. (1996). Einleitung. In A. Bühler \& L. Cataldi Madonna (Eds.), Georg Friedrich Meier, Versuch einer allgemeinen Auslegungskunst (1757), Vol. 482 of Philosophische Bibliothek (pp. VII-IC). Hamburg: Felix Meiner Verlag.

Carnap, R. (1930). Die alte und die neue Logik. Erkenntnis, 1, 12-26.

Cavell, S. (1958). Must we mean what we say? Inquiry, 1, 172-212.

Chadwick, J. (1990). The decipherment of linear B (2nd ed.). Cambridge: Cambridge University Press.

Chalmers, D. (1996). The conscious mind: In search of a fundamental theory. Oxford: Oxford University Press.

Duhem, P. (1906). La théorie physique: son objet, sa structure. Paris: Rivière (cited from P. Wiener's translation, The Aim and Structure of Physical Theory, Princeton: Princeton University Press, 1991).

Gettier, E. (1963). Is justified true belief knowledge? Analysis, 23, 121-123.

Goldman, A. I. (1976). Discrimination and perceptual knowledge. Journal of Philosophy, 73(20), 771-791.

Grundmann, T. (2003). Der Wahrheit auf der Spur. Eine Verteidigung des erkenntnistheoretischen Externalismus. Paderborn: Mentis.

Hazlett, A. (2009) The myth of factive verbs. Philosophy and Phenomenological Research (to appear).

Johnston, M. (1992). How to speak of the colors. Philosophical Studies, 68, 221-263.

Karlsson, F. (2008). Early generative linguistics and empirical methodology. In A. Lüdeling, \& M. Kytö (Eds.), Corpus linguistics. An international handbook (Vol. 1, pp. 14-38). Berlin: De Gruyter.

Kauppinen, A. (2007). The rise and fall of experimental philosophy. Philosophical Explorations, 10(2), 95-118.

Kuhn, T. S. (1957). The Copernican revolution. Cambridge MA: Hardard University Press.

Kuipers, T. A. F. (2007). Explication in philosophy of science. In T. A. F. Kuipers (Ed.), Handbook of the philosophy of science. General philosophy of science-focal issues (pp. vii-xxiii). Amsterdam: Elsevier.

Lewis, D. K. (1983). Philosophical papers, Vol. 1. Oxford: Oxford University Press.

Löwe, B., Müller, T., \& Müller-Hill, E. (2009). Mathematical knowledge: A case study in empirical philosophy of mathematics. In: B. Van Kerkhove, J. De Vuyst, \& J. P. Van Bendegem (Eds.), Philosophical perspectives on mathematical practice. London: College Publications.

Mates, B. (1958). On the verification of statements about ordinary language. Inquiry, 1, 161-171.

Mele, A. R. (2003). Motivation and agency. Oxford: Oxford University Press.

Müller-Hill, E. (2009) Formalizability and knowledge ascriptions in mathematical practice. Philosophia Scientiae 13(2) (to appear).

Nagel, E. (1961). The structure of science. New York: Hartcourt, Brace and World.

Nemeth, E. (2007). Logical empiricism and the history and sociology of science. In A. Richardson \& T. E. Uebel (Eds.), Cambridge companion to logical empiricism (pp. 278-302). Cambridge: Cambridge University Press.

Putnam, H. (1975). The meaning of 'meaning'. In Mind, language, and reality. Philosophical papers (Vol. 2, Chapter 12, pp. 215-271). Cambridge: Cambridge University Press. 
Quarteroni, A. (2009). Mathematical models in science and engineering. Notices of the American Mathematical Society, 56(1), 10-19.

Russell, B. (1948). Human knowledge: Its scope and limits. London: Allen and Unwin.

Ryle, G. (1949). The concept of mind. New York: Barnes and Noble.

Schleiermacher, F. (1838). Hermeneutik und Kritik mit besonderer Beziehung auf das Neue Testament, Vol. I.7 of Friedrich Schleiermacher's saemmtliche Werke. Berlin: G. Reimer. Aus Schleiermachers handschriftlichem Nachlasse und nachgeschriebenen Vorlesungen herausgegeben von Dr. Friedrich Lücke.

Scholz, O. R. (2001). Verstehen und Rationalität, Vol. 76 of Philosophische Abhandlungen. Frankfurt a.M.: Vittorio Klostermann.

Schütze, C. T. (1996). The empirical base of linguistics. Grammaticality judgments and linguistic methodology. Chicago: University of Chicago Press.

Sosa, E. (2007). Experimental philosophy and philosophical intuition. Philosophical Studies, 132, 99-107.

Swain, S., Alexander, J., \& Weinberg, J. M. (2008). The instability of philosophical intuitions: Running hot and cold on truetemp. Philosophy and Phenomenological Research, 76(1), 138-155.

Symons, J. (2008). Intuition and philosophical methodology. Axiomathes, 18, 67-89.

Uebel, T. (2001). Carnap and Neurath in exile: Can their disputes be resolved? International Studies in the Philosophy of Science, 15, 211-220.

Weinberg, J. M., Nicholas, S., \& Stich, S. (2001). Normativity and epistemic intuitions. Philosophical Topics, 29(1\&2), 429-460.

Williamson, T. (2004). Philosophical 'intuitions' and scepticism about judgment. Dialectica, 58(1), $109-153$.

Wittgenstein, L. (1953). Philosophische Untersuchungen / Philosophical Investigations. Oxford: Blackwell (edited posthumously and published together with an English translation by E. Anscombe). 